\title{
INÍCIO DE OPERAÇÃO E ESTABILIZAÇÃO DA SINTERIZAÇÃO DA CSP*
}

\author{
Luiz Fernando Pimentel Simões ${ }^{1}$ \\ Ulisses Tetti \\ Eduardo Casagrande $\mathrm{Neto}^{3}$ \\ Alisson Dias da Silva
}

\section{Resumo}

Neste trabalho são apresentados o planejamento e preparação para o início da operação, o período de "ramp up" e estabilização da produção da sinterização da Companhia Siderúrgica do Pecém. Incluindo a estruturação e execução do comissionamento; elaboração dos procedimentos para operação aliado a implantação do sistema de gestão da qualidade; definição do quadro de pessoal, seleção, contratação e treinamento; definição das especificações de matériasprimas, aquisição dos primeiros lotes, com desenvolvimento de fornecedores locais; apresentação dos resultados dos principais indicadores de produção e qualidade no período de "ramp up" e estabilização da planta.

Palavras-chave: Comissionamento; Início da Operação; "Ramp Up”; Estabilização.

\section{START UP AND STABILIZATION OF CSP'S SINTER PLANT}

\begin{abstract}
In this work are presented the planning and preparation for the start up, the ramp up period and stabilization of the sintering production of Companhia Siderúrgica do Pecém. Including the structuring, planning and execution of commissioning; Elaboration of the procedures for operation together with the implementation of the quality management system; Definition of staff, selection, hiring and training; Definition of raw material specifications, acquisition of the first lots, with development of local suppliers; Presentation of the results of the main indicators of production and quality in the period of ramp up and stabilization of the plant.
\end{abstract}

Keywords: Commissioning; Start Up; Ramp Up; Stabilization.

1 Engenheiro Metalurgista, MBA, Analista de Processos Sr; Gerência Técnica da Redução, Companhia Siderúrgica do Pecém, São Gonçalo do Amarante, Ceará, Brasil.

2 Engenheiro Metalurgista, M.sc., Especialista de Sinterização, Gerência Técnica da Redução, Companhia Siderúrgica do Pecém, São Gonçalo do Amarante, Ceará, Brasil.

3 Engenheiro Metalurgista, MBA, Gerente de Tecnologia; Gerência Geral de Redução, Companhia Siderúrgica do Pecém, São Gonçalo do Amarante, Ceará, Brasil.

4 Engenheiro Metalurgista, Coordenador de Operação da Sinterização; Gerência de Operação da Sinterização, Companhia Siderúrgica do Pecém, São Gonçalo do Amarante, Ceará, Brasil. 


\section{INTRODUÇÃO}

A CSP (Companhia Siderúrgica do Pecém), situada na ZPE (Zona de Processamento de Exportação) do complexo portuário do Pecém, no município de São Gonçalo do Amarante, no estado do Ceará, é uma siderúrgica integrada, projetada para uma produção 3.000 .000 t/ano de placas.

A planta de sinterização da CSP possui capacidade instalada para produção de 4.715.800 t/ano de sinter, equivalente a uma produtividade de $32,3 \mathrm{t} / \mathrm{m}^{2} / \mathrm{dia}$ com índice operacional de $98 \%$. A tabela abaixo exibe os dados dos principais equipamentos da planta:

Tabela 1. Dados dos principais equipamentos da planta sinterização

\begin{tabular}{|c|c|c|c|c|}
\hline $\begin{array}{c}\text { Área Útil da Máquina de } \\
\text { Sinter }\end{array}$ & Exaustor Principal & Misturador de Tambor & Resfriador Circular & Sopradores do Resfriador \\
\hline $400 \mathrm{~m}^{2}(4 \mathrm{~mL} \times 100 \mathrm{~m} \mathrm{C})$ & $2 \times 18.000 \mathrm{~m}^{3} / \mathrm{min}$ & $2 \times 1.080 \mathrm{th}$ & $1.050 \mathrm{th}$ & $2 \times 18.000 \mathrm{~m}^{3} / \mathrm{min}$ \\
\hline
\end{tabular}

O objetivo desse trabalho é apresentar a preparação e planejamento para início da operação da sinterização da CSP e os resultados de fato obtidos na partida, "ramp up" e estabilização da planta.

\section{MATERIAIS E MÉTODOS}

\subsection{Planejamento e Preparação Para o Start Up}

\subsubsection{Comissionamento}

O comissionamento, em linhas gerais, foi divido em três etapas, sendo: Précomissionamento, comissionamento a frio e, por fim, comissionamento a quente. Estrategicamente, para realização do comissionamento, a Sinterização foi dividida em grupos de equipamentos, totalizando sete grupos:

- Dosagem e linha de mistura;

- Moagem;

- Despoeiramentos;

- Máquina e resfriador de sinter;

- Linha de produto;

- Utilidades;

- Pátio de sinter.

Em linhas gerais, as fases de pré-comissionamento e comissionamento a frio, contemplaram os seguintes testes:

- Testes de sinal e de continuidade (parte elétrica);

- Testes individuais de cada equipamento (local e remoto);

- Testes de grupo e geral;

- Teste de interface com os equipamentos de outras plantas a jusante e montante;

Nos testes de sinal e de continuidade, foi verificada a continuidade de todo o cabeamento da planta, e a resposta de sinal dos equipamentos e sensores 
simulando sinais das possíveis falhas dos equipamentos e verificando a transmissão.

Nos testes individuais foram verificadas as condições de cada equipamento individualmente, verificando parâmetros como vibração, temperatura, etc.

Nos testes de grupo e geral, foram verificados os intertravamentos, condições para partida/parada dos equipamentos, considerando as interfaces entre estes.

Por último, o teste de interfaces, verificou as interfaces (comunicação/ intertravamentos) com as plantas a montante e a jusante.

$\mathrm{Na}$ figura e tabela abaixo, podemos observar os principais marcos a serem realizados antes do comissionamento a quente, ou seja, início da operação:

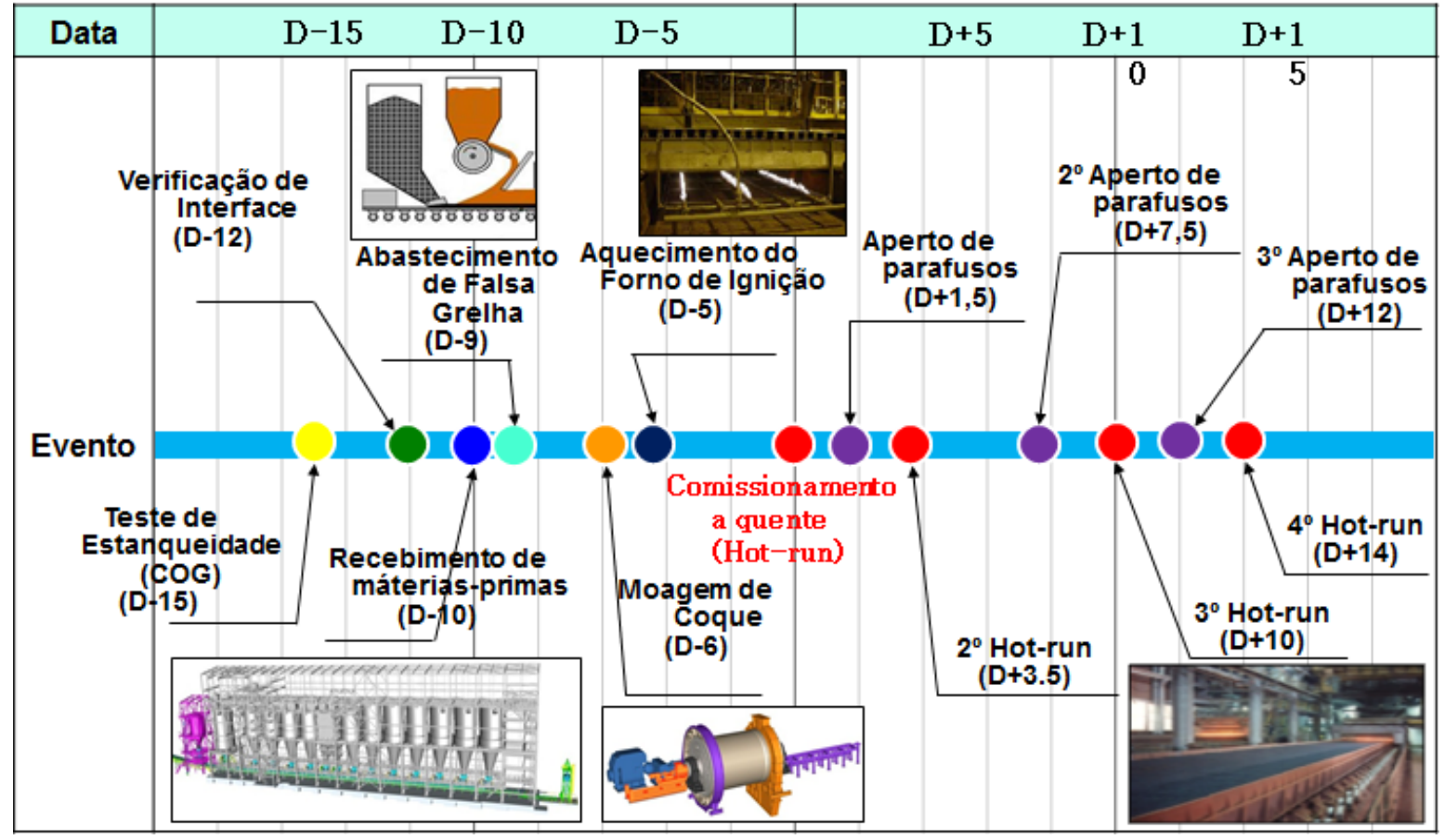

Figura 1. Marcos para o comissionamento a quente.

Tabela 2. Descrição dos principais marcos para o comissionamento

\begin{tabular}{|c|c|c|}
\hline Data & Evento & Descrição \\
\hline D-15 & Teste de estanqueidade (GCO) & $\begin{array}{c}\text { Injetar nitrogênio na tubulação de GCO e verificas o } \\
\text { desvio de pressão }\end{array}$ \\
\hline D-12 & Verificação de interface & $\begin{array}{c}\text { Verificar a interface de comunicação (sinal) com as } \\
\text { outras plantas }\end{array}$ \\
\hline D-10 & Recebimento de matérias-primas & $\begin{array}{l}\text { Receber matérias-primas nos silos da dosagem } \\
\text { para o inicio da operação. }\end{array}$ \\
\hline D-9 & Abastecimento de falsa grelha & Abastecer pelotas na tremonha de falsa grelha. \\
\hline D-7 & Recebimento de cal & $\begin{array}{l}\text { Receber cal dos fornecedores no silo de cal da } \\
\text { sinterização }\end{array}$ \\
\hline D-7 & Recebimento de coque e GCO & $\begin{array}{l}\text { Recebimento de GCO e coque como combustivel } \\
\text { (inserir barras no moinho de barras) }\end{array}$ \\
\hline D-6 & Partida da moagem de coque & $\begin{array}{l}\text { Moer o coque e peneira-lo em } 5 \mathrm{~mm} \text {, enviando o } \\
\text { passante aos silos da dosagem. }\end{array}$ \\
\hline D-5 & $\begin{array}{l}\text { Aquecimento do forno de ignição } \\
\text { (cura do refratário) }\end{array}$ & $\begin{array}{l}\text { Ligar chama piloto (D-5) } \\
\text { Ligar queimador principal (D-2) }\end{array}$ \\
\hline D-0 & Hot-run & $\begin{array}{c}\text { Primeiro Sinter } \\
\text { (Destinado ao pátio de sinter como lastro) }\end{array}$ \\
\hline
\end{tabular}


2.1.2 Elaboração de procedimentos, manuais e estruturação do sistema de gestão.

A CSP enfrentou um cenário bem desafiante no inicio de suas operações. Operar com $70 \%$ da mão de obra local (sem experiência em ambientes industriais semelhantes ao siderúrgico) e certificar seu sistema de gestão de qualidade em paralelo à partida da usina. Para sustentar esse cenário, foi necessário um esforço desempenhado desde 2014 na preparação de documentação para estruturação do sistema de gestão e treinamento do pessoal.

A partir dos manuais dos equipamentos entregues pelos fabricantes, foram desenvolvidos manuais de treinamento específicos de forma didática para treinamento da mão de obra local.

Com base nos manuais dos equipamentos, em treinamentos ministrados por pessoal experiente da Posco e na experiência previa de $30 \%$ da mão de obra contratada, conforme ABNT [1] foram desenvolvidos os fluxos de processo e operação, procedimentos técnicos e operacionais, para padronizar a operação da Sinterização e respaldar o sistema de gestão da qualidade.

\subsubsection{Definição do quadro de pessoal, contratação e treinamento.}

O projeto da CSP, por ser situado na ZPE possui uma serie de concessões fiscais. A contrapartida esperada pelo governo do estado é o desenvolvimento da economia do estado e criação de emprego para a população. Com esse intuito, foi estabelecido um acordo para que $70 \%$ da mão de obra da empresa fosse local.

A economia cearense, não possui tradição na indústria de base, como ocorre no caso das outras usinas siderúrgicas situadas no sudeste, portanto, não há mão de obra local disponível com experiência industrial, como ocorre no sudeste. Dado este cenário, foi necessário, traçar um programa de formação de operadores que foi feito em parceria com o SENAI. Na figura abaixo, podemos observar a linha do tempo com as principais etapas do programa de capacitação desenvolvido:

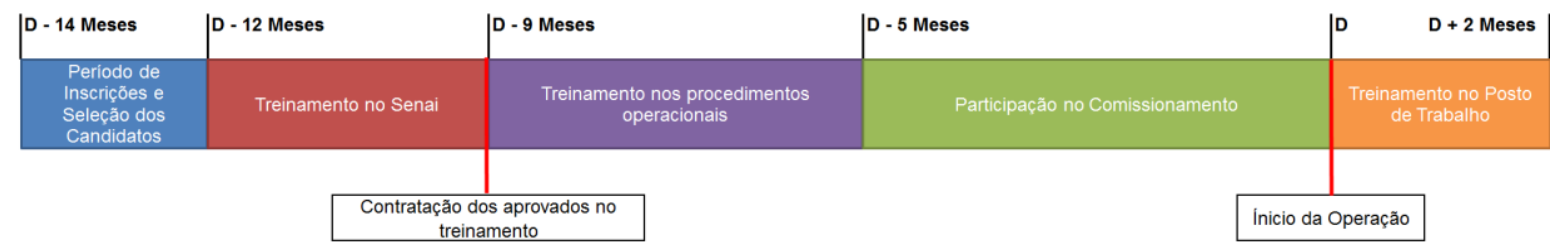

Figura 2. Linha de tempo do programa de formação de operadores.

$\mathrm{Na}$ etapa do SENAI, ocorreu treinamento em normas de segurança, siderurgia básica e treinamento específico da área de destinação dos operadores, utilizando os manuais dos equipamentos elaborados, já mencionados no tópico anterior.

Para compor o restante da mão de obra ligada a operação, os $30 \%$ restantes, foram contratadas pessoas com experiência prévia em siderurgia, ou em indústrias afins. Pessoal que foi destinado principalmente aos cargos de liderança, incumbidos de capacitar os $70 \%$ inexperientes, trabalhando como "padrinhos" destes.

Com o fim do programa do SENAI, e o ingresso na CSP, ficou a cargo destes padrinhos darem continuidade no programa de formação ministrando treinamento nos procedimentos e acompanhando os operadores em treinamento durante 0 comissionamento e treinamento no posto de trabalho. Esta ultima etapa foi finalizada com base na avaliação realizada pelos "padrinhos" e por uma banca técnica formada 
pela liderança. Neste momento ouve uma cerimonia na qual foi retirada a identificação "em treinamento" que estes operadores utilizavam.

\subsubsection{Matérias-Primas}

A sinterização da CSP utiliza as seguintes matérias-primas em seu processo:

- Minério de ferro (sinter feed);

- Areia fina de alta sílica;

- Calcário dolomítico fino;

- Calcário calcítico fino;

- Finos de coque;

- Antracito fino;

- Cal virgem fina;

- By-product (mistura de subprodutos das várias plantas da usina);

- Retornos de finos (gerados nos peneiramentos do processo).

Tendo como foco a definição das especificações de matérias-primas, aquisição dos primeiros lotes, com desenvolvimento de fornecedores locais para a Sinterização, não iremos abordar os finos de coque, By-product e retornos de finos, pois não foram adquiridos externamente pela Sinterização.

Primeiramente, tratando do sinter feed, a definição dos minérios a serem utilizados, veio junto à concepção do projeto, na qual a Vale, que possui $50 \%$ do capital do projeto, foi estabelecida como responsável pelo fornecimento da fonte ferrífera do processo. Sendo assim, foi estabelecida uma mistura com sinter feed proveniente de Carajás em conjunto com sinter feed de alta sílica, proveniente do eixo Sudeste embarcado no porto de tubarão.

Para o caso do antracito, foi estabelecida uma especificação, tendo como referência os padrões utilizados na Posco, e foi adquirido o material realizando processo licitatório, utilizando critérios técnicos e comerciais, no mercado internacional. Sendo que a primeira carga foi de um antracito russo.

Os fundentes, ou seja, areia, calcários e cal, necessitaram de um empenho maior, com desenvolvimento de fornecedores locais. Para o caso da cal, tendo em vista que há necessidade de um investimento de longo prazo, foi firmado um contrato de longo prazo, com dois fornecedores, que instalaram uma planta de calcinação na região da Chapada do Apodi no município de Quixeré no Ceará. Por motivos de atrasos no processo de instalação e partida das plantas de calcinação destes dois fornecedores e estratégia comercial, foi firmada parceria com um terceiro fornecedor, também localizado na Chapada do Apodi, porém no município de Baraúna no Rio Grande do Norte.

O calcário calcítico foi adquirido de dois fornecedores do Ceará, que desenvolveram o processo de extração e beneficiamento, focado em atingir a especificação estabelecida pela CSP. A equipe técnica da CSP apoiou o desenvolvimento, realizando visitas periódicas nas plantas dos fornecedores e esclarecendo os critérios necessários para adequação do material ao processo de sinterização. Posteriormente foi comprado um lote de calcário canadense e um terceiro fornecedor está em desenvolvimento, de acordo com a politica de estratégia comercial da CSP de ampliar as possibilidades de fornecimento, melhorando as perspectivas de negociação técnico-comercial. 
O calcário dolomítico, assim como o calcítico, também foi fornecido por duas empresas localizadas no Ceará que desenvolveram e adaptaram suas plantas para atender a demanda e características especificas do produto requerido pela CSP.

Para o fornecimento de areia fina de alta sílica, inicialmente foi encontrado somente um fornecedor capaz de atender a especificação de qualidade estabelecida pela equipe técnica da Sinterização. Hoje há um segundo fornecedor em desenvolvimento. Na tabela abaixo, podemos observar a especificação estabelecida para as matérias-primas da sinterização:

Tabela 3. Especificação dos fundentes e antracito da sinterização

\begin{tabular}{|c|c|c|c|c|c|}
\hline \multirow[b]{2}{*}{ Item } & \multicolumn{5}{|c|}{ Especificação por Matéria-Prima } \\
\hline & Calcário Calcítico & Calcário Dolomítico & Areia & Cal & Antracito \\
\hline $\mathrm{CaO}$ & $\min 54,0 \%$ & $\min 31,5 \%$ & - & $\min 93,5 \%$ & - \\
\hline $\mathrm{SiO} 2$ & máx 1,5\% & máx 2,0\% & $\min 95,0 \%$ & máx 2,5\% & - \\
\hline $\mathrm{MgO}$ & máx $1,0 \%$ & $\min 17,5 \%$ & - & máx $1,0 \%$ & - \\
\hline P2O5 & máx $0,05 \%$ & - & - & máx $0,1 \%$ & - \\
\hline $\mathrm{Al} 2 \mathrm{O} 3$ & máx $0,6 \%$ & - & - & máx $1,0 \%$ & - \\
\hline Reatividade (HCl 10min) & - & - & - & $\min 360$ & - \\
\hline $\mathrm{S}$ & - & - & - & - & máx $0,6 \%$ \\
\hline $\mathrm{N}$ & - & - & - & - & máx $1,2 \%$ \\
\hline Ash & - & - & - & - & máx $9,5 \%$ \\
\hline Material Volátil & - & - & - & - & máx $10,0 \%$ \\
\hline Carbono Fixo & - & - & - & - & $\min 76,0 \%$ \\
\hline Umidade & máx $5,0 \%$ & máx 5,0\% & máx 5,0\% & máx $1,5 \%$ & máx $10,0 \%$ \\
\hline$\leq 10,0 \mathrm{~mm}$ & - & - & - & - & $\min 80,0 \%$ \\
\hline$>5,0 \mathrm{~mm}$ & máx 3,0\% & - & - & - & - \\
\hline$\geq 1 \mathrm{~mm} \leq 5,0 \mathrm{~mm}$ & $\min 60,0 \%$ & - & - & - & - \\
\hline$<3,36 \mathrm{~mm}$ & - & - & $100,0 \%$ & - & - \\
\hline$>3,36 \mathrm{~mm}$ & - & máx $5,0 \%$ & - & - & - \\
\hline$<3,0 \mathrm{~mm}$ & - & - & - & $100,0 \%$ & - \\
\hline$>1,0 \mathrm{~mm}$ & - & 25,0 a $30,0 \%$ & - & - & - \\
\hline$<0,105 \mathrm{~mm}$ & máx $10,0 \%$ & máx $20,0 \%$ & máx $20,0 \%$ & - & máx 5,0\% \\
\hline
\end{tabular}

Para os casos da cal e do antracito, a especificação foi definida tomando como base a referência da Posco e de outras siderúrgicas brasileiras. Já para o caso da areia, calcários dolomítico e calcítico, além dessas referências, foram utilizados estudos científicos para embasar a especificação.

Hosotani [2] estabelece que o índice de granulação da mistura a sinterizar é melhorado com a utilização de calcário concentrado na faixa granulométrica de 1,0 a $5,0 \mathrm{~mm}$. A granulação da mistura impacta diretamente na permeabilidade do leito a sinterização e consequentemente na produtividade da sinterização. Além disso, Hosotani [2] estabelece que a concentração do calcário nessa faixa granulométrica aliada a utilização de moinha de coque com granulometria concentrada na faixa de 0,5 a $5,0 \mathrm{~mm}$ beneficia a resistência mecânica do sinter, demostrado pela melhora do índice de degradação sob-redução (RDI) e justificado pelo aumento da formação de magnetita e cálcio ferrita acicular finamente dispersa. Baseado nesse estudo foi estabelecido uma especificação mínima a ser atingida para essa faixa granulométrica.

Para o caso da areia, Higuchi [3] realiza testes em planta piloto utilizando areia em granulometria na qual é baseada a especificação da CSP. O mesmo Higuchi [3] realiza testes para diferentes granulometrias de calcário dolomítico, e chega a conclusões que para obtenção de maior produtividade aliada a maior rendimento e resistência mecânica do sinter o ideal é que o top size seja de 3,0 mm e o tamanho médio de $1,0 \mathrm{~mm}$. Baseado nesta configuração ideal foi estabelecida a especificação granulométrica do calcário dolomítico. 


\subsection{Qualidade do primeiro sinter}

A especificação de qualidade do primeiro sinter foi definida pela equipe técnica do Alto Forno, de acordo com as necessidades para o primeiro carregamento e partida do Alto Forno. Inicialmente a qualidade estabelecida foi conforme tabela abaixo:

Tabela 4. Especificação do sinter para partida da planta

\begin{tabular}{|c|c|c|c|c|c|c|c|c|c|}
\hline Unidade & $\mathrm{FeO}$ & $\mathrm{CaO}$ & $\mathrm{SiO} 2$ & MgO & Al2O3 & $\mathrm{CaO} / \mathrm{SiO} 2$ & Shatter Index & RDI & $<5,0 \mathrm{~mm}$ \\
\hline$\%$ & $\leq 8,0$ & $9,58 \pm 0,3$ & $5,32 \pm 0,2$ & $1,10 \pm 0,2$ & $\leq 1,40$ & $1,80 \pm 0,05$ & $\geq 92,0$ & $\leq 35,0$ & $\leq 5,0$ \\
\hline
\end{tabular}

Posteriormente, foi requerida uma redução de basicidade do sinter gradativa até atingir 1,70 com intuito de reduzir a geração de escória no alto forno (menor necessidade de utilização de quartzo para manter a mesma basicidade da escória do forno).

Tetti [4] propõe metodologia para cálculo do leito de sinterização. Esta foi a metodologia utilizada para o leito inicial determinando a proporção relativa de cada matéria-prima para início da operação com objetivo de atingir a qualidade exposta na tabela 3. Os cálculos seguintes decorrentes das mudanças na especificação do sinter e de lotes das matérias-primas permaneceram utilizando o mesmo método.

\section{RESULTADOS E DISCUSSÃO}

O início da operação da sinterização ocorreu em treze de maio de 2016. Os eventos seguintes à partida, apresentados na figura 1 da seção anterior, sofreram modificações em decorrência do desempenho operacional na partida superior às expectativas e em adequação a data de partida do Alto Forno.

A primeira produção de sinter foi destinada ao pátio de sinter, para formar o lastro. $O$ objetivo inicial foi de adequar o sinter a especificação estabelecida o mais rápido possível para então destinar a produção ao abastecimento dos silos do Alto Forno. O tempo necessário para esta adequação foi mais breve que o esperado. Inicialmente a expectativa era que no primeiro evento de partida da planta, toda a produção seria destinada ao estoque. Somente após a parada para manutenção e retorno (segunda partida), o sinter seria destinado a abastecer os silos do Alto Forno.

O que de fato ocorreu, é que já no dia 16/05/2016, quarto dia de operação, com a qualidade química dentro da especificação, o sinter foi destinado ao abastecimento dos Silos do Alto Forno. Na figura abaixo pode ser observada a variação do Shatter Index, nos primeiros dias de operação, que foi o principal critério para aceitação para o abastecimento dos silos do Alto Forno: 


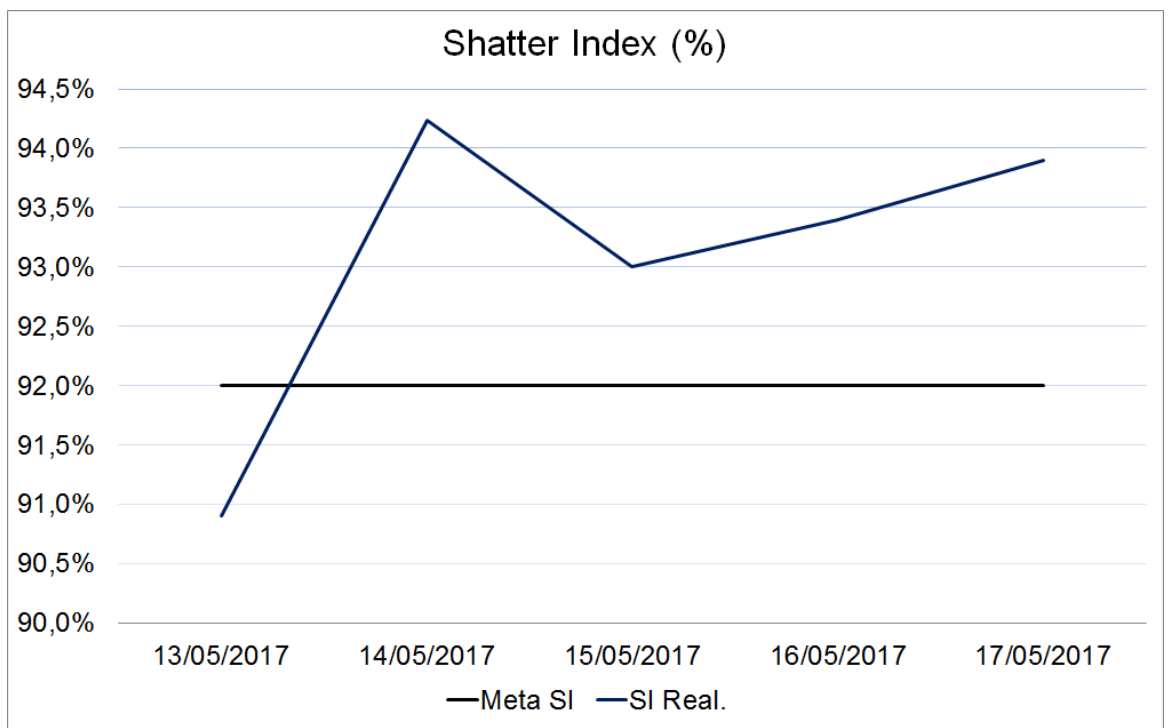

Figura 3. Gráfico de resultados do Shatter Index nos primeiros dias de operação.

Notando a estabilidade do SI acima da meta especificada, foi iniciado o abastecimento dos silos no dia 16/05 data na qual foram abastecidos $2061 \mathrm{t}$. Depois disso a produção voltou a ser destinada ao estoque, no dia 18/05 a operação foi interrompida para realizar reaperto dos parafusos dos equipamentos conforme planejamento exposto na figura 1 da seção anterior.

A operação da Sinterização foi reestabelecida no dia 23/05, mantendo operação até o dia 25/05. No dia 25/05 foram abastecidos mais 3847 toneladas de sinter nos silos do Alto Forno, o restante da produção do período foi destinada à formação de estoque.

Em seguida, estão apresentadas figuras com os resultados dos principais indicadores de produção e de qualidade da Sinterização no ano da data da partida até maio/2017 (compreendendo partida, ramp-up e estabilização) seguidas de cada uma delas estão os comentários referentes aos resultados:

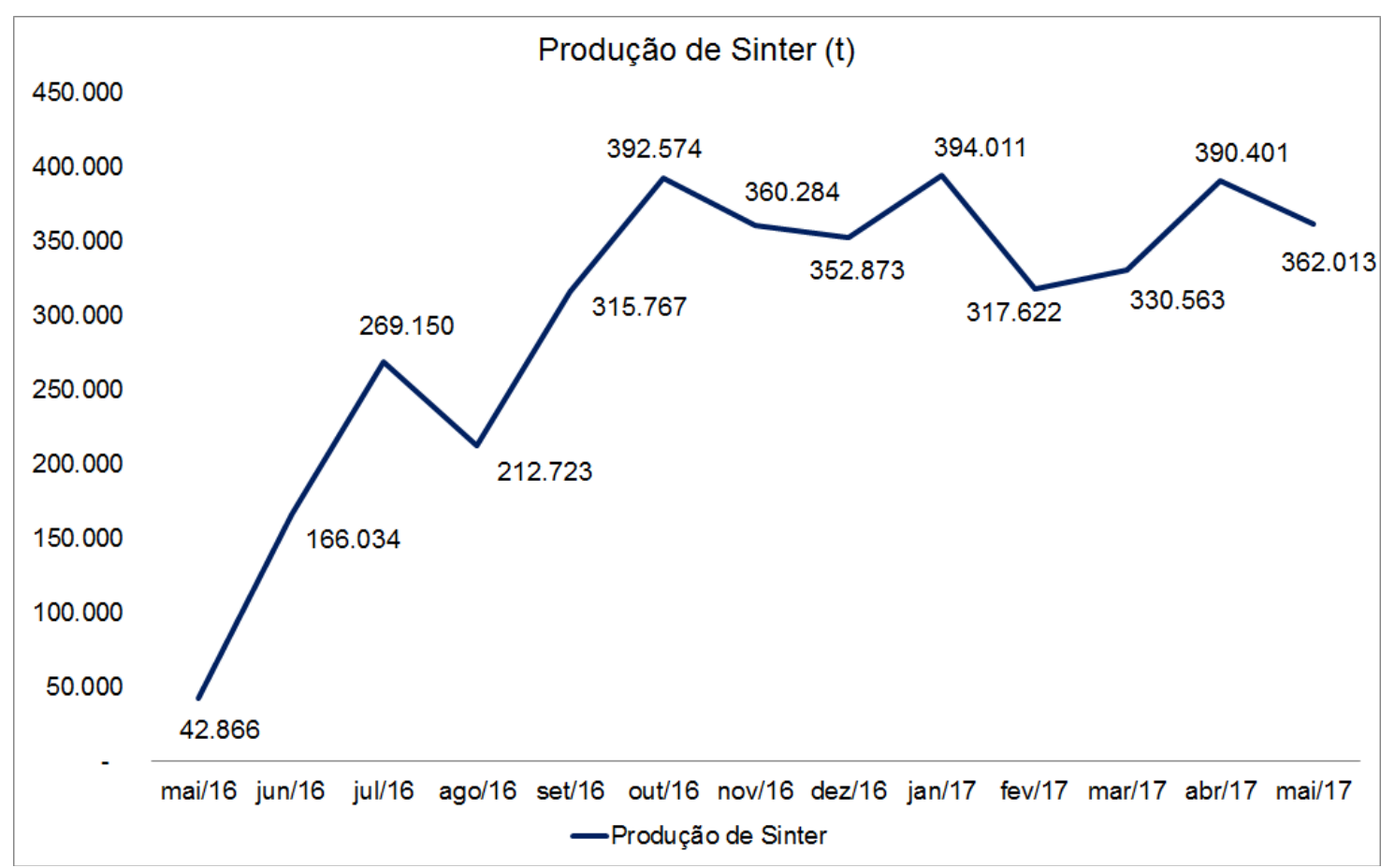

Figura 4. Gráfico da produção de mensal de sinter. 


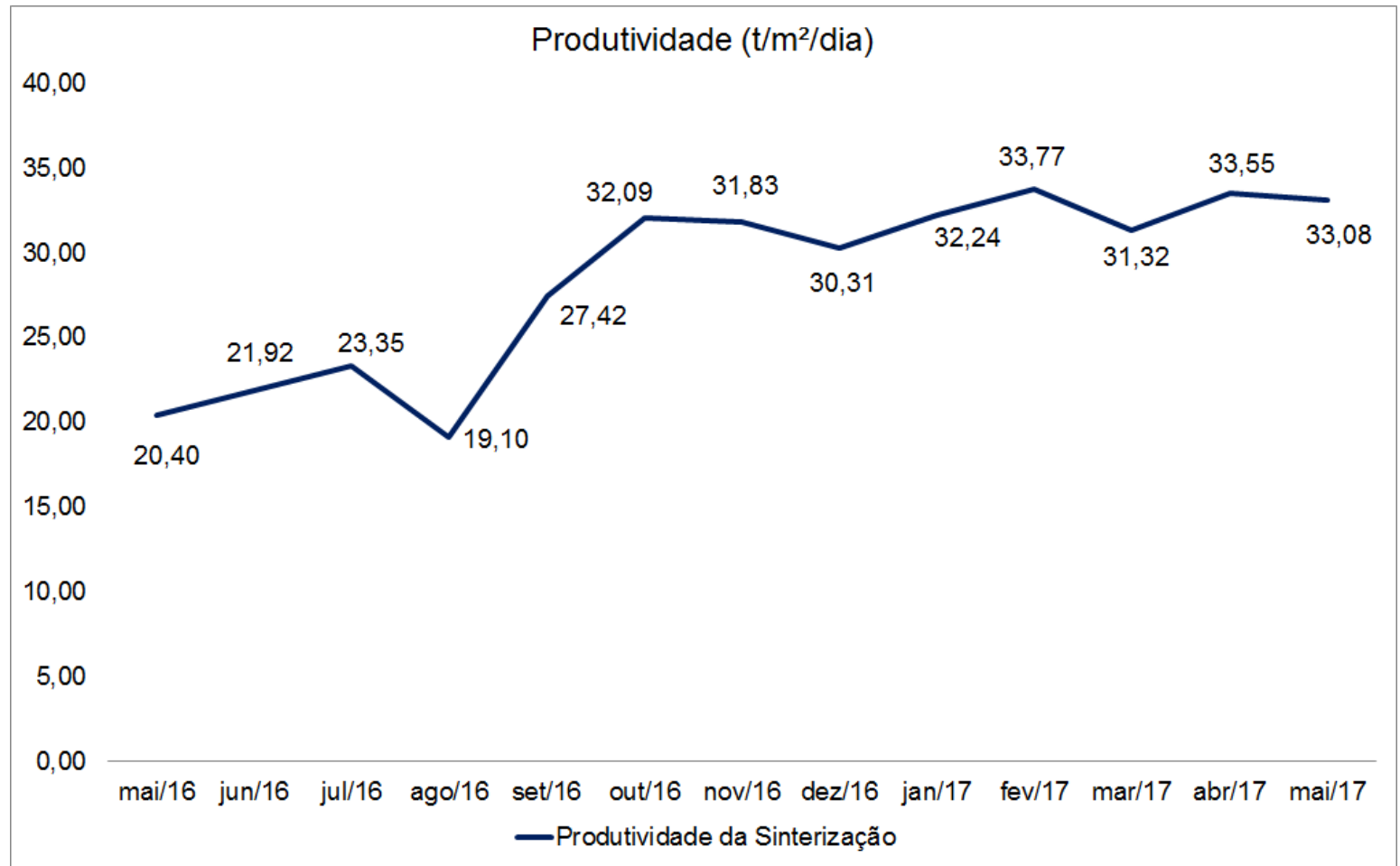

Figura 5. Gráfico da produtividade mensal da sinterização.

A produção e produtividade da sinterização demoraram a serem elevadas, chegando próximo ao nominal de projeto, somente no mês de outubro, por dois motivos principais: adequação da produção ao consumo do Alto Forno (controle de estoque) e limitações do sistema de descarga de minério do porto para abastecimento da usina.

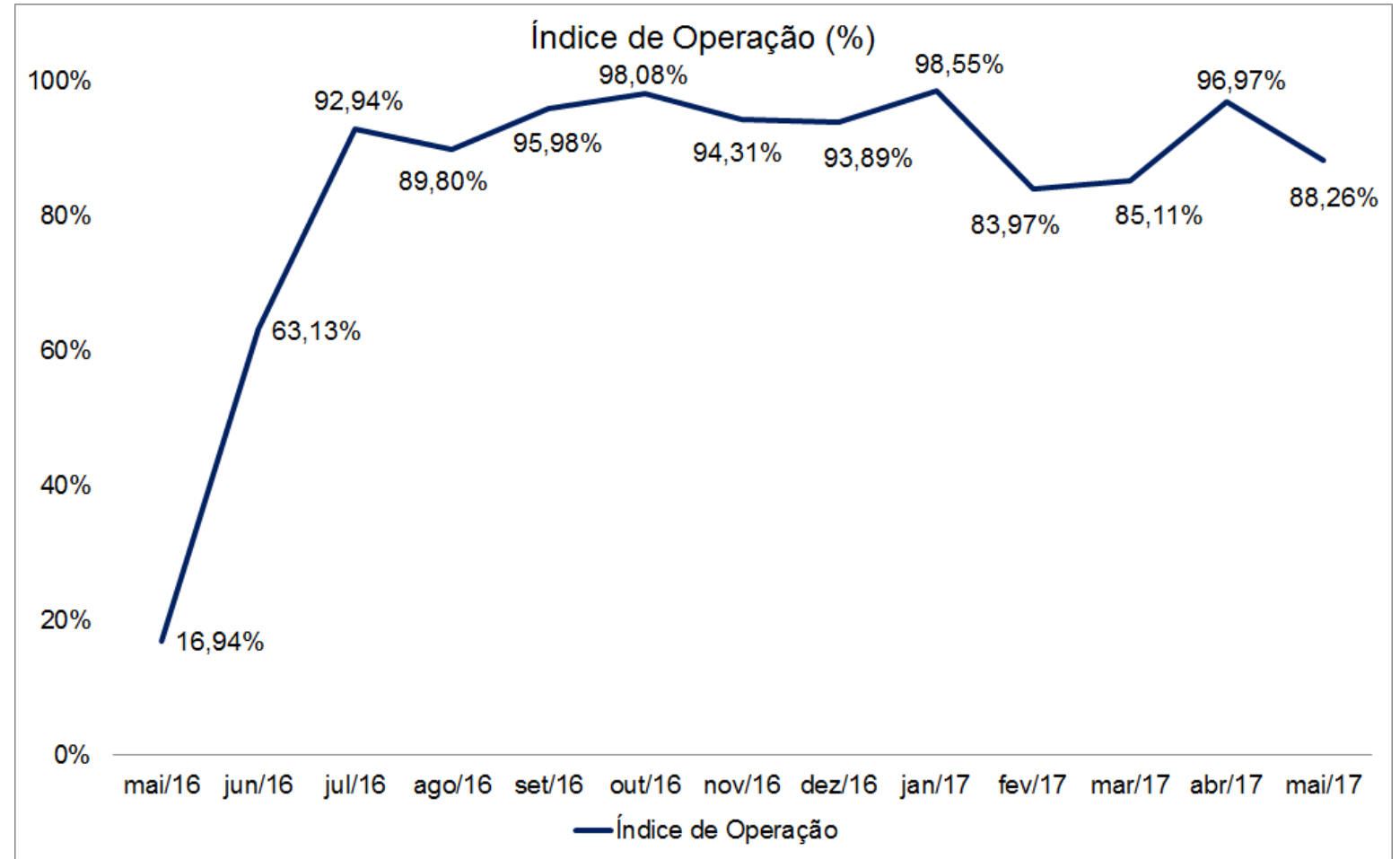

Figura 6. Gráfico do índice de operação mensal da sinterização. 
No gráfico da figura 6 pode ser observado o aumento e estabilização do índice de operação da sinterização. Os índices de fev, mar e mai/17, estão mais baixos, pois a sinterização foi parada em decorrência de paradas na Aciaria e Alto Forno.

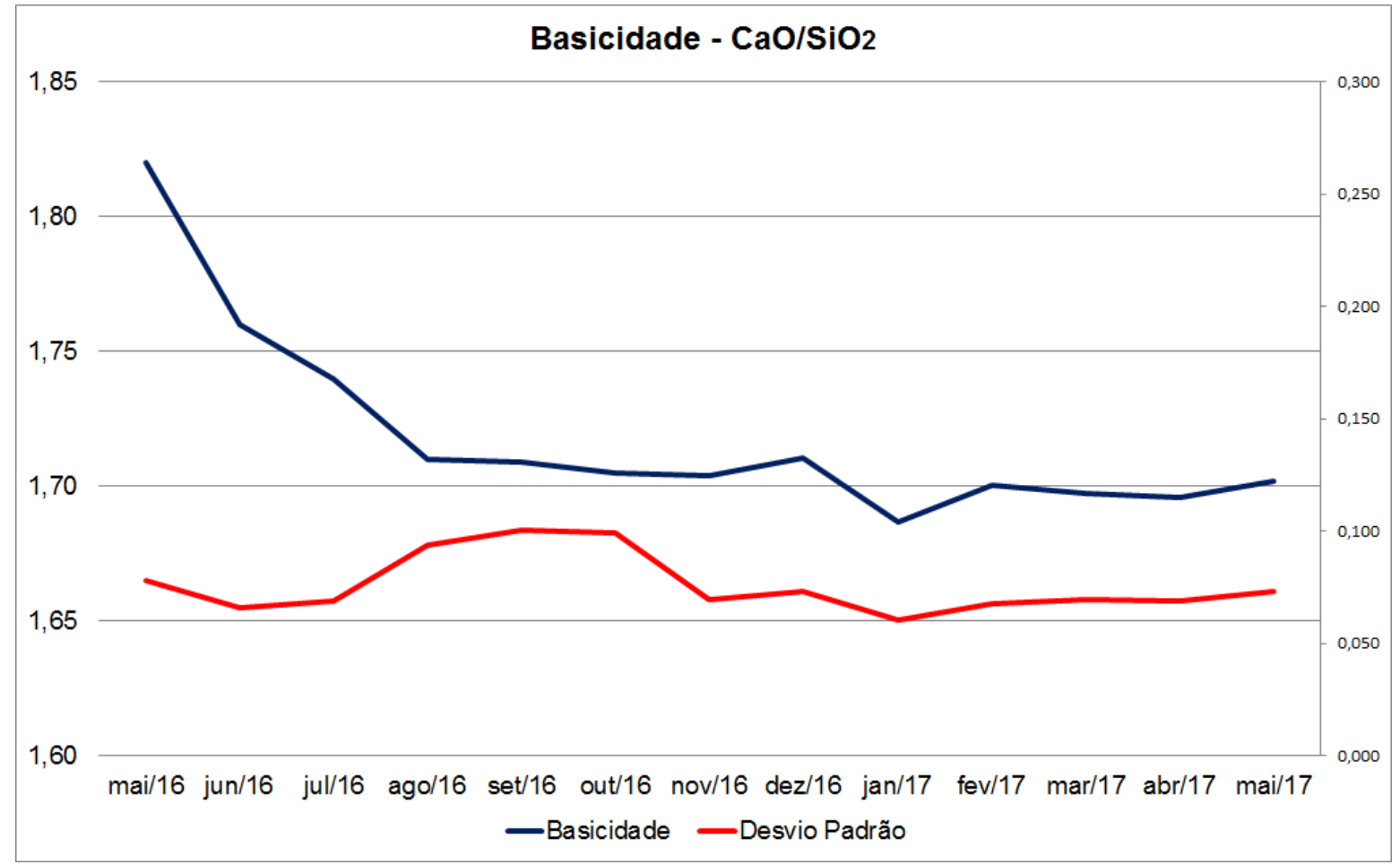

Figura 7. Gráfico da média mensal da basicidade do sinter.

Gráfico da figura 7 mostra os resultados da basicidade, que conforme dito anteriormente, iniciou a operação com especificação de 1,80 e gradualmente foi alterada até $1,70 \mathrm{com}$ intuito de diminuir volume de escória no Alto Forno.

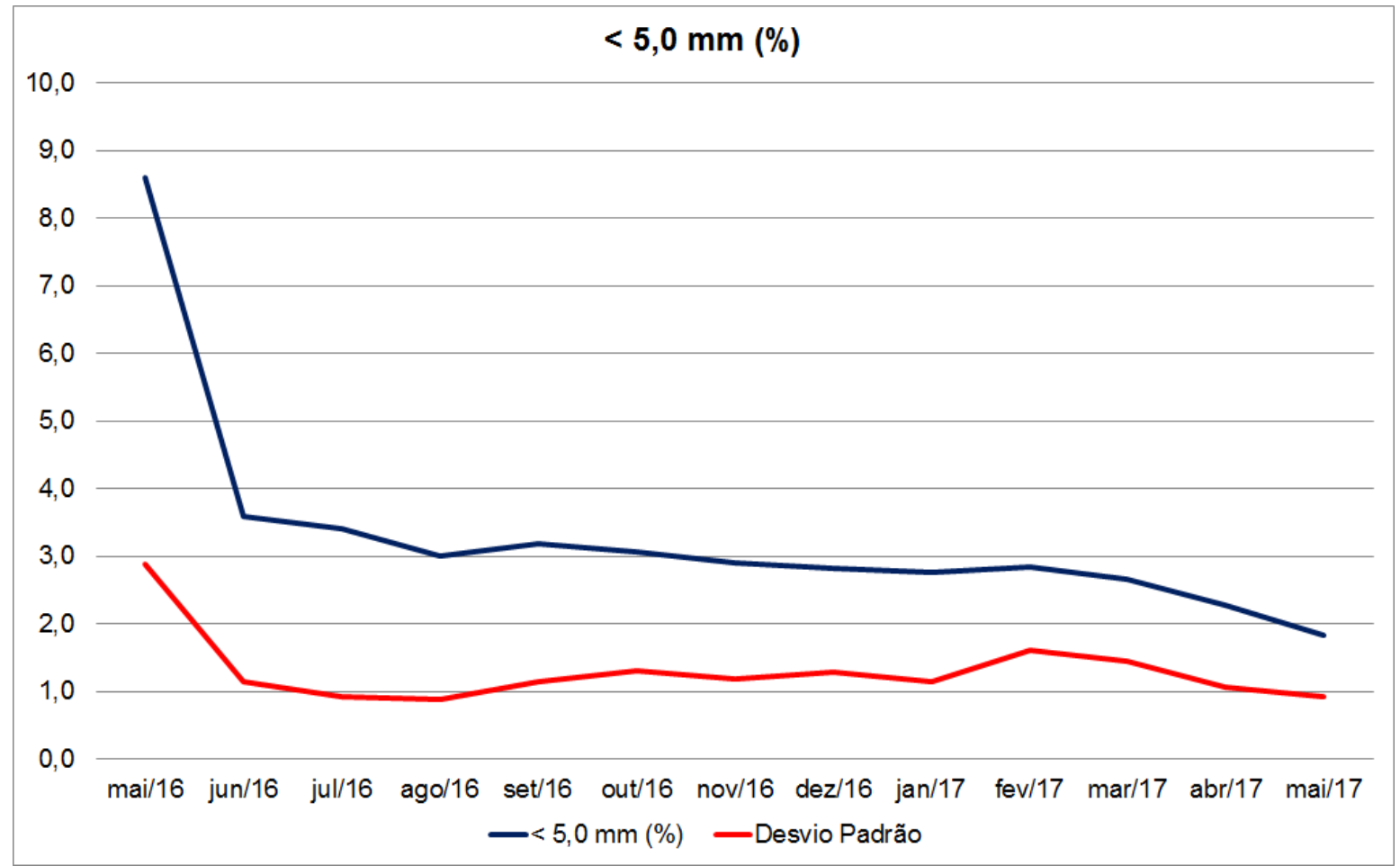

Figura 8. Gráfico da média mensal de $<5,0 \mathrm{~mm}$ do sinter. 
Gráfico da figura 8 mostra resultados do percentual de sinter $<5,0 \mathrm{~mm}$ pode ser observada uma queda abrupta do mês de maio para os demais meses. Durante o inicio das operações, foi constatado que a configuração das malhas do terceiro peneiramento da sinterização estava adaptada para um diâmetro de corte de 4,0 $\mathrm{mm}$ e, além disso, com configuração propicia para obstrução de malhas. Foi realizada uma melhoria, com alteração do projeto e substituição das malhas. 0 resultado foi uma melhora imediata no índice.

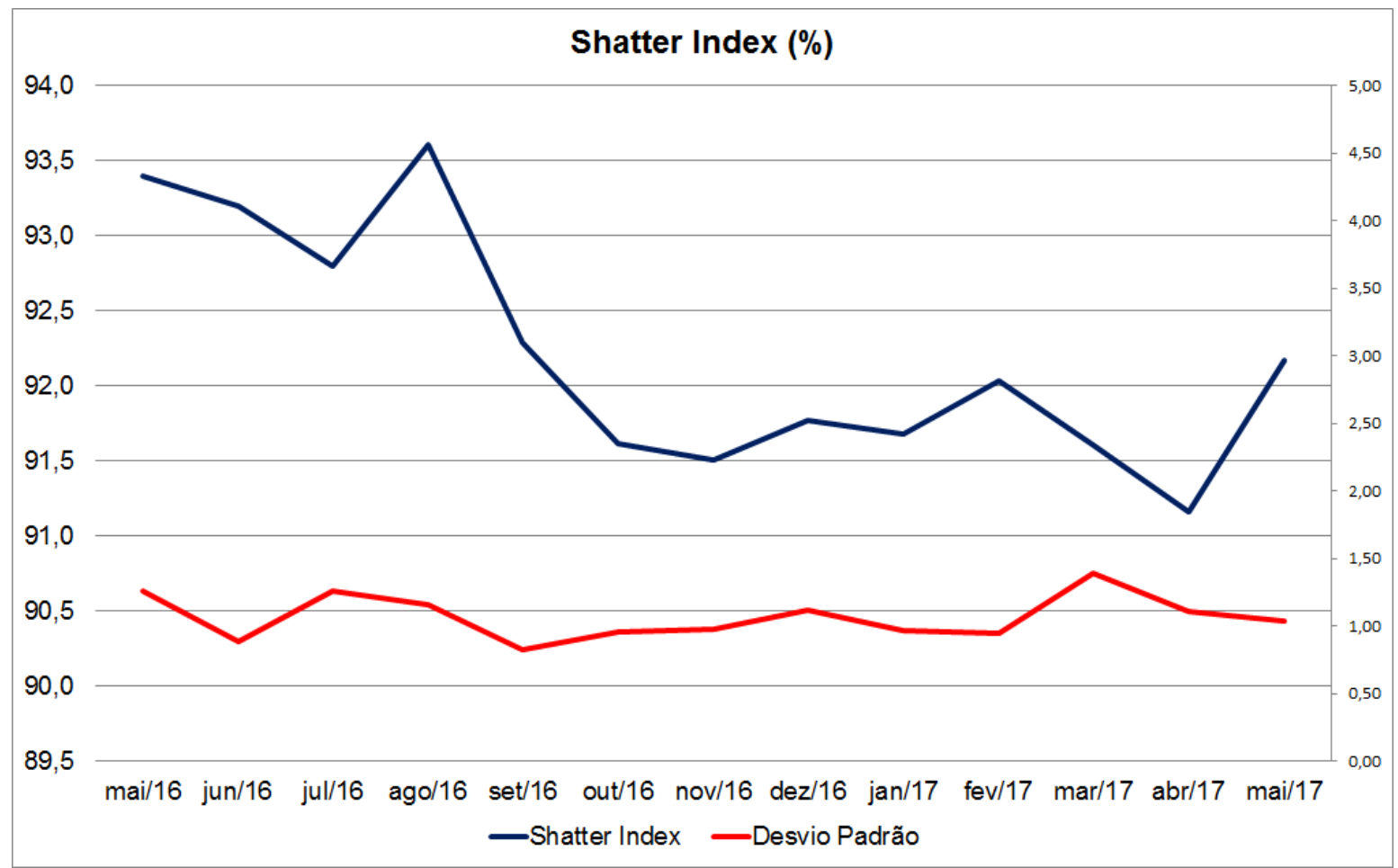

Figura 9. Gráfico da média mensal do shatter index do sinter.

Pode ser observada no gráfico da figura 9 uma tendência de queda nos resultados do índice, principalmente a partir do mês de outubro. Loo [5] em seu estudo mostra que com o aumento da produtividade na sinterização, há uma diminuição do tempo em que a mistura a sinterizar fica exposta a altas temperaturas (superiores a $1000^{\circ} \mathrm{C}$ ) que são responsáveis por garantir a resistência mecânica ao sinter. Podemos observar que, justamente no mês de outubro, houve uma elevação maior da produtividade da Sinterização, mantida nos meses seguintes. Portanto, é possível associar a elevação na produtividade com a queda no Shatter Index, que retrata a resistência mecânica do sinter, assim como demonstrado no estudo de Loo [5].

\section{CONCLUSÃO}

O inicio da operação da planta de sinterização da CSP foi um sucesso como um todo, não tendo eventos significativos que prejudicaram o resultado. Deve-se exaltar a dificuldade de obter tal resultado, pois além de um equipamento novo, se trata de uma empresa nova, com $70 \%$ da mão de obra de operação inexperiente. Todo o planejamento e estruturação para a partida, enfatizando o desenvolvimento dos procedimentos de operação, o comissionamento, o desenvolvimento de fornecedores de matéria-prima locais e o programa de formação dos operadores, devem ser exaltados. 
A qualidade do sinter de forma geral está estável e atendendo a especificação. 0 desafio atual é aumentar a produtividade, mantendo bons resultados de resistência mecânica - Shatter Index. A produção está estável e o equipamento apresenta bons índices de operação, mais baixo em alguns meses em adequação ao consumo do Alto Forno.

\section{REFERÊNCIAS}

1 ASSOCIAÇÃO BRASILEIRA DE NORMAS TÉCNICAS.NBR ISO 9001/2015: Sistemas de Gestão da Qualidade. Rio de Janeiro, 2015.

2 Hosotani Y, Konno N, Yamaguchi K, Orimoto T, Inazumi T. Reduction Properties of Sinter with Fine Dispersed Pores at High Temperatures of $1273 \mathrm{~K}$ and Above. ISIJ International. 1996;36(12):1439-1447.

3 Higuchi K, Tanaka T, Sato T. Reaction Behavior of Dolomite Accompanied with Formation of Magnetite Solid Solution in Iron Ore Sintering Process. ISIJ International. 2007;47(5):669-678.

4 Tetti U, Silva MHRT, Lima IT, Junior AV. Desenvolvimento de um Balanço de Massas na Sinterização - Estudo do Teor de Minério de Fósforo do Sinter. In Associação Brasileira de Metalurgia, Materiais e Mineração. XXIV Seminário de Redução de Minério de Ferro: Qualidade Total Aplicada à Área de Redução; 1993; Vitória, Brasil.

5 Loo CE, Dukino RD. Laboratory Iron Ore Sintering Studies. 3. Critical Heat Transfer Period. Mineral Processing and Extractive Metallurgy. 2014;123(4):204-211. 